\title{
Advances in Atrial Fibrillation Ablation
}

Editors

LUIGI DI BIASE

FRANCIS MARCHLINSKI

ANDREA NATALE

\section{CARDIAC \\ ELECTROPHYSIOLOGY CLINICS}

www.cardiacEP.theclinics.com

Consulting Editors

RANJAN K. THAKUR

ANDREA NATALE

June 2020 • Volume 12 - Number 2 